\title{
THE EFFECT OF LEADERSHIP STYLE ON EMPLOYEE JOB SATISFACTION
}

\author{
Muhammad Ahsanullah Khan ${ }^{1}$ and Usman Ali Waraich ${ }^{2}$
}

\begin{abstract}
This paper aims to determine the effect of leadership styles on employee job satisfaction. A survey was conducted by administering questionnaires to 400 respondents in different organizations within Pakistan. Transformational leadership style was seen to have a positive effect on various facets of employee job satisfaction. Transactional leadership also turned out to be perceived as having a positive effect on different facets of employee job satisfaction, so does empowering leadership. It was found that leaders and managers combine the various leadership styles identified in the research paper in proportions that produce a positive result when administering their leadership duties. The proportions at which these leadership styles are combined depend on the nature of the situation they encounter in the workplace.
\end{abstract}

Keywords: Small \& Medium Sized Enterprises; Social Media Marketing; Transactional Marketing Mechanisms.

\section{INTRODUCTION}

The basic ideologies of the global socio-economic development in the 21 st century have been abruptly transformed due to massive technological advancements and disruptions. The recent past decades have witnessed a substantial rise in global attention and interest in entrepreneurship subject, particularly in small and medium enterprises. This concentration can be synchronized in the realm of evolving global economic concerns, escalating poverty

\footnotetext{
$1 \& 2$ Institute of Business Management
} 
incidences, relentless income inequalities, altering social structures, and widening socioeconomic gaps. The increased interest in the small and medium enterprises upholds a valid approach, considering the comprehensive research evidence that asserts the small and medium firms to be a critical driving force of economic progress (Kharub \& Sharma, 2020). SMEs significantly contribute to the Gross Domestic Product (GDP), increase productivity, enhance tax revenues, create tremendous employment opportunities, and aid the balance of trade through exports thus, enormously add to the overall economic output (Gherghina, Botezatu, Hosszu, \& Simionescu, 2020; Chong et al. 2019; Tripathi, 2019).

The SMEs role to stimulate the economic cycle is particularly predominant in developing economies, where the proportion of the human capital workforce to the available employment opportunities is relatively small. Similarly, the contribution of SMEs in Pakistan is consistent with the other developing economies. The SMEs constitute over ninety percent (90\%) of the 3.2 million businesses enterprises listed under the Economic Census of Pakistan, generate twenty-five percent (25\%) of manufacturing export earnings, contribute thirty-five percent $(35 \%)$ to the manufacturing value addition and nearly thirty percent (30\%) to the annual GDP. Besides, SMEs in Pakistan employ nearly eighty percent (80\%) of the non-agricultural labor force and are a source of livelihood to millions of people.

What distinguishes SMEs is that unlike large enterprises that are considered an integral part of the formal economy, most small and medium enterprises fall within the "less formally organized sector" according to SMEDA (2005). They have limited access to financial resources and are limited in their scale of operation. This inherent feature makes SMEs dependent on government infrastructural support that may relate, inter alia, to preferential treatment in the allocation of credit, institutional support for technical up-gradation and the development of skilled human resources.

Currently, the new wave of social media trend has taken the majority of the world populace into its influence. Consumers comprising a diverse range of demographic cohort including boomers to generation $\mathrm{Z}$ and the new generation Alpha, all are seen accustomed to social media handling. Similarly, the emerging micro and small businesses run by the people belonging to this cluster are observed to be more inclined to find new promotional channels for their businesses, through the social media platform. This study is thus intended to explore prospects and opportunities of the use of social media tools by SMEs to develop and promote their businesses. Although it is a thriving trend, social media can benefit SMEs as much as, if not more than large size enterprises. The social media operates on a less complex organizational 
structure, requires lower financial investments, and even makes an organization appear to be larger than its actual size, which makes it favorable to the SMEs ${ }^{11}$.

Consequently, this paper will focus on how small businesses can utilize the social media tools not only for advertising and marketing of their products and services but also building the business overall, by means of transactional mechanisms, sharing information with customers and receiving their feedback and recommendations on a regular basis. In developing economies due to financial and other institutional barriers, SMEs face genuine problems in leveraging customers and cannot afford the colossal advertising budgets that the more established, more affluent "big business" can, either at the national level or globally.

\section{LITERATURE REVIEW}

\section{Background of the Study}

Leadership style is considered as a major subject for researchers because it is still an attractive attribute about leadership among academics and managers As well, the attention to leadership style has come for subordinates since they like to work more effectively and productively when their managers adopted a specific leadership style. Thus, leadership style is the most important item of leadership process, since managers develop leadership style via their education, training, and experience. That let leadership to be one of the most social phenomena, which have been examined, and it is significant for the effectiveness of functions in both business and society organizations. Job satisfaction is considered as an important goal in organizations for two reasons. First, employees deserve respect and fair treatment. Second, employees' job satisfaction will affect the functions of organization. Furthermore, reported that satisfied employees are less absent, stay at work, and they have positive contributions to their organizations, while dissatisfied employees are more absent, show job stress, and look for new job (Al-ababneh 2015).

\section{Statement of Problem}

Leadership styles can either motivate or discourage employees, which in return can cause employee's increase or decrease in their level of performance. According to (Belonio, 2012) the sources of employee job dissatisfaction include inadequate salary, conflicting job demands (from the leadership) and absence of promotion prospects. For efficiency purposes, an effective leadership style, one that positively affects employees' satisfaction and results in better 
performances, effectiveness and productivity is clearly desirable (Belonio 2012). This paper aims to determine the effect of leadership styles on employee job satisfaction.

\section{Research Questions}

RQ1: How is transformational Leadership related to employee's job satisfaction?

RQ2: How is transactional Leadership related to employee's job satisfaction?

RQ3: How is empowering Leadership related to employee's job satisfaction?

\section{OBJECTIVES OF STUDY}

In this study, the researcher investigates the extent to which three leadership styles (namely, transformational, transactional, and empowering influence employees' job satisfaction, by examining how leadership style enhances the level of job satisfaction.

\section{JUSTIFICATION/ SIGNIFICANCE OF STUDY}

The findings will benefit, supporting a more universal approach to leadership style preferences rather than a 'beauty is in the eye of the beholder' or cultural perspective to leadership style. Particularly, age groups, firm tenure, national location and industry effects supported propositions of the effectiveness of different approaches to leadership in general. It will enhance the level of employee's job satisfaction by adopting appropriate leadership style.

\section{Limitation of Study}

Some of the respondents' failure to fill the questionnaires without making sure that the information was correct on the one hand and time constraints on the other were the two main limitations encountered in conducting this research paper.

Another limitation is that our questionnaires answered were not covering the target population entirely which might not be the complete opinion each and every employee working in all sectors of different industries.

\section{SCOPE OF THE STUDY}

The research scope of this study was the Pakistani manufacturing and service providing industry; while this limitation may limit the generalizability of the findings, a key objective was to assess the impact of leadership style in this specific cultural situation. The study drew a 
broad cross-section through the Pakistani industry by covering different areas and by including different types of industries. Further research on this subject can investigate if study findings can be applied to other industries and other countries

\section{Assumptions}

The following assumptions were made according to this study. First, as with earlier studies and theory, it was assumed that effective leadership style was situational. This view was based on the proposition that differing beliefs and values of different situations will present different methods or practices contingent on the culture. Cultural elements of interest in this study included national culture (Pakistan). Because other factors may impact leadership practice and perceptions, age and length of tenure with the firm were included as control variables of interest.

\section{LITERATURE REVIEW}

\section{Introduction}

Most firms and businesses consist of employers and employees or, put differently, management and staff or leaders and followers. Most of them are goal oriented. In order to achieve the desired objectives, there must be an interaction between employers and employees (or management and staff or leaders and followers) (Belonio 2012).

The leadership style that characterizes the interaction between leaders (or managers) and their followers (or staff members) is most important in terms of employees' efficiency and productivity (Belonio 2012)

Employees are the workforce of any businesses and they carry out the duties required to achieve the desired objective of any firm. Employee satisfaction is impacted by the employees' perception of their job and the organization for which they work for. Employees' perception of leadership behavior is an important predictor of employee job satisfaction and commitment). Individual perception of the organization is related to job attitudes (Belonio 2012)

Leadership styles can either motivate or discourage employees, which in return can cause employee's increase or decrease in their level of performance. The sources of employee job dissatisfaction include inadequate salary, conflicting job demands (from the leadership) and absence of promotion prospects (Belonio 2012) 
For efficiency purposes, an effective leadership style, one that positively affects employees' satisfaction and results in better performances, effectiveness and productivity is clearly desirable) (Belonio 2012).

The various schools of thought about leadership and leadership styles will be fully documented in the literature review part of this article. The conceptual framework and methodology will then be considered. Next, the findings will be discussed and recommendations made (Belonio 2012).

\section{Transformational Leadership}

(Rothfelder, Ottenbacher, and Harrington 2012) Characterized transformational leadership as being composed of four behavioral components, which are unique but interrelated idealized influence, inspirational motivation, intellectual stimulation and individualized consideration. The first two dimensions represent the notion of 'charisma' and are based on a follower's admiration for a leader, in equal measures as a follower's confidence in a leader's vision and his or her values. The third dimension, intellectual stimulation is concerned with providing followers with challenging tasks. Individualized consideration, as the last transformational dimension, describes the degree to which leaders are concerned with the follower's individual needs and wants. As all four transformational dimensions start with the letter 'I', literature often refers to them as the 'four I's'. (Rothfelder et al. 2012) found that transformational leaders achieve higher results by employing one or more of the transformational dimensions.

\section{Transactional Leadership}

Transactional leadership behavior is composed of three dimensions: contingent reward, active management-by-exception and passive management by-exception. Contingent rewarding leaders get agreement on what needs to be done by followers and provide rewards in exchange for effective task completion. Management-by-exception can be practiced either actively or passively. The active form is mainly based on constant monitoring and taking corrective action, whereas, at the passive form of management- by-exception, corrective actions are only taken if things go wrong (Rothfelder et al. 2012) In earlier research (Rothfelder et al. 2012), found that subordinates of transactional leaders experience lower overall work satisfaction than the subordinates of transformational leaders. Here again, little research has been performed to demonstrate this relationship with specific dimensions of transactional leadership and if these 
relationships hold in differing cultural contexts. To bridge this gap in the literature, this study aimed to analyze the influence of contingent reward and management-by-exception on employee job satisfaction, individually.

\section{Empowering Leadership}

Empowering leadership represents a significant paradigm shift and emphasizes follower selfinfluence rather than external, top-down influence Leaders who use empowering behaviors believe that followers are an influential source of wisdom and direction. These leaders emphasize self-influence; self-management; self-control; or, to use term, self-leadership (Yun et al. 2007)

\section{Transactional Leadership's Impact on Employees' Job Satisfaction}

Transactional managers (often in concert with subordinates) determine and define the goals and work that subordinates need to achieve, suggest how to execute their tasks, and provide feedback. This process should assist employees in becoming confident about meeting their role requirements. Transactional supervisors also recognize the immediate needs of their subordinates and communicate to employees how those needs will be met (what organizational rewards they will receive) through effective performance. As a result, subordinates presumably will be directed and motivated to accomplish their goals. A fully implemented example of this contractual relationship between salespersons and their transactional leader is typified by the sign above the sales manager's desk in a commission-oriented sales organization that reads, "NO ORDERS, NO MONEY (Dubinsky et al. 1995).

Transformational Leadership's Impact on Employees’ Job Satisfaction:

Transformational leadership raise subordinates' awareness of the importance and value of designated outcomes, get employees to transcend their own self-interests for the sake of the group or organization, and change or increase subordinates' needs (Dubinsky et al. 1995). Through such means, employees' motivation and self-confidence are enhanced. To accomplish these results, transformational leaders possess and display four key characteristics (Dubinsky et al. 1995): charismatic leadership, inspirational leadership, intellectual stimulation, and individualized consideration. 


\section{Empowering Leadership's Impact on Employees' Job Satisfaction}

If the leader is a real empowering leader, he or she recognizes the potential of the followers to be self-leaders as well as the importance of the team process, interaction, and collaboration among the members in the team-based context. This recognition makes the empowering leader emphasize teamwork, collaboration, or interaction among team members as well as individual self-initiative in doing their work. Also, empowering leaders influence followers to recognize the importance of teamwork, interaction, collaboration, or extra-role behaviors which can make teamwork more harmoniously in the team-based context. Thus, empowering leaders can increase team citizenship behaviors directly or indirectly through job satisfaction (Yun et al. 2007).

\section{Hypothesis}

H1: There is a positive relationship between transformational leadership style and employees' job satisfaction.

H2: There is a positive relationship between transactional leadership style and employees' job satisfaction.

H3: There is a positive relationship between empowering leadership style and employees' job satisfaction.

\section{RESEARCH METHODS}

\section{Research Design}

The type of research was quantitative or explanatory type where the independent variables were available in the literature and were explained in this research and the model was made and theory was tested. The research method used was mono research, and its scope was basic because it covered almost all employees of all the industrial sectors. Technique of research was secondary since the information was gathered from previously conducted studies. The approach of research was deductive since the research was conducted on all industrial scale employees and can be specified to any industry or organization. Time horizon in this research can be considered as cross sectional because single respondents were supposed to answer the data for single time. The study setting was natural since no leader was made to change his or her original leadership style from those they possess from the given three. The type of 
investigation was correlational since it could not be said that the change in dependent variable was purely because of the change in leadership style. While the statistical technique used was Chi-square since all the variables were qualitative.

\section{Population and Sample}

\section{Sampling Unit}

Sampling unit was considered an individual person. Since individuals working in different sectors and organizations were used to collect data.

\section{Sampling Technique}

Sampling technique used was probability sampling since the sampling frame could be known.

\section{Sample Size}

Sample size taken is 384 as population size is vast. Confidence level is taken as $95 \%$. Confidence interval is 5 .

\section{Instrumentation}

\section{Variables}

There were four variables in all and all of them were qualitative, unidimensional unobserved variables.

Transformational Leadership: This variable was independent variable which was measured under 12 items adopted from literature whose reference is given below.

Transactional Leadership: This variable was independent variable which was measured under 3 items adopted from literature whose reference is given below.

Empowering Leadership: This variable was independent variable which was measured under 10 items adopted from literature whose reference is given below.

Employee Job Satisfaction: This variable was dependent variable which was measured under 2 items adopted from literature whose reference is given below.

\begin{tabular}{|c|c|c|c|c|}
\hline \multirow[t]{2}{*}{ Variables } & \multicolumn{2}{|c|}{ Items } & Scaling & Reference \\
\hline & & $\begin{array}{l}\text { He/she is not afraid to "break the mold" to find } \\
\text { different ways of doing things. } \\
\text { He/she isn't bound by tradition when it comes to } \\
\text { getting things done. }\end{array}$ & $\begin{array}{l}\text { All items were } \\
\text { measured using }\end{array}$ & \\
\hline
\end{tabular}




\begin{tabular}{|c|c|c|c|c|}
\hline $\begin{array}{l}\text { Transformational } \\
\text { Leadership }\end{array}$ & 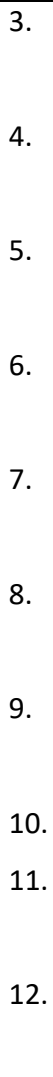 & $\begin{array}{l}\text { He/she isn't afraid to "buck the system" if } \\
\text { he/she thinks it is necessary. } \\
\text { He/she is a non-traditional type who "shakes up } \\
\text { the system" when necessary. } \\
\text { He/she challenges established ways of doing } \\
\text { things. } \\
\text { He/she strives towards higher purposes or } \\
\text { ideals. } \\
\text { He/she has a strong personal dedication to } \\
\text { higher purposes or ideals. } \\
\text { He/she provides a clear vision of who and what } \\
\text { we are. } \\
\text { Because of him/her, I have a clear vision of our } \\
\text { organization. } \\
\text { He/she is driven by higher purposes or ideals. } \\
\text { He/she provides a clear vision of where we are } \\
\text { organization to me. }\end{array}$ & $\begin{array}{l}\text { a five-point } \\
\text { response format } \\
1 \text { (definitely not } \\
\text { true) } \\
2 \text { (not true) } \\
3 \text { (neither true } \\
\text { nor untrue) } \\
4 \text { (true), } \\
5 \text { (definitely } \\
\text { true)]. }\end{array}$ & $\begin{array}{l}\text { (Yun et al. } \\
\text { 2007) }\end{array}$ \\
\hline $\begin{array}{l}\text { Transactional } \\
\text { Leadership }\end{array}$ & $\begin{array}{l}1 . \\
2 . \\
3 .\end{array}$ & $\begin{array}{l}\text { My manager shows me that he/she recognizes } \\
\text { my accomplishments. } \\
\text { When I do good work, my manager commends } \\
\text { me. } \\
\text { My manager points out what I will receive if I do } \\
\text { what needs to be done. }\end{array}$ & $\begin{array}{l}(0 \bullet \text { "not at all" } \\
\text { and } \\
4 \bullet \text { "frequently. } \\
\text { if not always") }\end{array}$ & $\begin{array}{l}\text { (Dubinsky et } \\
\text { al. 1995) }\end{array}$ \\
\hline $\begin{array}{l}\text { Empowering } \\
\text { Leadership }\end{array}$ & $\begin{array}{l}3 . \\
4 .\end{array}$ & $\begin{array}{l}\text { He/she urges me to work as a team with other } \\
\text { mangers/supervisors who report to him/her. } \\
\text { He/she encourages me to work together with } \\
\text { other managers/supervisors who report to } \\
\text { him/her. } \\
\text { He/she advises me to work together with other } \\
\text { managers/supervisors who report to him/her as } \\
\text { a team. } \\
\text { He/she advises me to coordinate my efforts with } \\
\text { other managers/supervisors who report to } \\
\text { him/her. } \\
\text { He/she has a strong conviction in his/her own } \\
\text { beliefs and ideals. }\end{array}$ & $\begin{array}{l}\text { All items were } \\
\text { measured using } \\
\text { a five-point } \\
\text { response format } \\
1 \text { (definitely not } \\
\text { true) } \\
2 \text { (not true) }\end{array}$ & $\begin{array}{l}\text { (Yun et al. } \\
\text { 2007) }\end{array}$ \\
\hline
\end{tabular}




\begin{tabular}{|c|c|c|c|c|}
\hline & $\begin{array}{l}6 . \\
7 . \\
8 . \\
9 . \\
90 . \\
9 .\end{array}$ & $\begin{array}{l}\text { He/she urges me to search for solutions to my } \\
\text { problems on the job without his/her } \\
\text { supervision. } \\
\text { He/she advises me to solve problems when they } \\
\text { pop up without always getting his/her stamp of } \\
\text { approval. } \\
\text { He/she advises me to make improvements in } \\
\text { how I do my work on my own initiative without } \\
\text { being told } \\
\text { to do so. } \\
\text { He/she encourages me to find solutions to my } \\
\text { problems at work without seeking his/her direct } \\
\text { input. } \\
\text { He/she urges me to assume responsibilities on } \\
\text { my own. }\end{array}$ & $\begin{array}{l}3 \text { (neither true } \\
\text { nor untrue) } \\
4 \text { (true), } \\
5 \text { (definitely } \\
\text { true)]. }\end{array}$ & \\
\hline $\begin{array}{l}\text { Employees' Job } \\
\text { Satisfaction }\end{array}$ & & $\begin{array}{l}\text { Overall, I am very satisfied with my job. } \\
\text { I am very satisfied with the kind of work I do on } \\
\text { my job. }\end{array}$ & $\begin{array}{l}(0 \bullet \text { "not at all" } \\
\text { and } \\
4 \bullet \text { "frequently. } \\
\text { if not always") }\end{array}$ & $\begin{array}{l}\text { (Dubinsky et } \\
\text { al. 1995) }\end{array}$ \\
\hline
\end{tabular}

\section{RESULTS}

As per the questionnaires answered and the analysis of data gathered through them, we have inferred that all three of our hypotheses are accepted that are:

H1: There is a positive relationship between transformational leadership style and employees' job satisfaction.

H2: There is a positive relationship between transactional leadership style and employees' job satisfaction.

H3: There is a positive relationship between empowering leadership style and employees' job satisfaction.

As per this claim we had previously assumed that their there was positive dependency of transformational, transactional and empowering leadership on employee's job satisfaction and from the data analysis, hypothesis is accepted hence proving that transformational, 
transactional and empowering leadership do have positive relationship with employees job satisfy.

\section{DISCUSSION CONCLUSION AND RECOMMENDATION}

\section{Discussion and Conclusion}

The findings in this study show that managers (leaders) in different sectors and organizations in Pakistan combine various aspects or factors of leadership styles which depends on the working environment in which they operate. As seen in the above study, using various leadership styles produces various effects on job satisfaction and job satisfaction of an employee.

Transformational leadership was seen to have a positive effect on the significant subscales of job satisfaction. Transactional leadership also had a positive effect on the significant subscales of job satisfaction and empowering leadership had a positive effect as well on the significant subscales of job satisfaction. Since various factors of leadership styles affect various aspects of employee job satisfaction, which in turn affect job performance, managers, supervisors, leaders and organizational heads should not stick to only one form of leadership style. A combination of the various leadership styles will bring more satisfaction and enhance employee performance. They should therefore find the appropriate combinations of the leadership styles that would achieve the organizational goals together with the individual targets or objectives of the employees.

\section{RECOMMENDATIONS AND FUTURE DIRECTIONS}

Reviewing the literature indicated that leadership styles are different according to managers' demographic profiles. But this study was specifically limited to the organizations within the country Pakistan. In addition, job satisfaction among employees was varied based on their demographic profiles, and employees showed different attitudes towards their job satisfaction and job facets. action. 


\section{REFERENCES}

Al-Ababneh, M. (2013). Leadership style of managers in five-star hotels and its relationship with employee's job satisfaction. Available at SSRN 3633072.

Almutairi, D. O. (2016). The mediating effects of organizational commitment on the relationship between transformational leadership style and job performance. International Journal of Business and Management, 11(1), 231.

Bass, B. M. (1997). Personal selling and transactional/transformational leadership. Journal of Personal Selling \& Sales Management, 17(3), 19-28.

Belonio, R. J. (2012). The effect of leadership style on employee satisfaction and performance of bank employees in Bangkok. AU-GSB e-journal, 5(2).

Dai, Y. D., Dai, Y. Y., Chen, K. Y., \& Wu, H. C. (2013). Transformational vs transactional leadership: which is better? A study on employees of international tourist hotels in Taipei City. International Journal of Contemporary Hospitality Management.

Dubinsky, A. J., Yammarino, F. J., Jolson, M. A., \& Spangler, W. D. (1995). Transformational leadership: An initial investigation in sales management. Journal of Personal Selling \& Sales Management, 15(2), 17-31.

Nwokocha, I., \& Iheriohanma, E. B. J. (2015). Nexus between leadership styles, employee retention and performance in organizations in Nigeria. European Scientific Journal, 11(13).

Rothfelder, K., Ottenbacher, M. C., \& Harrington, R. J. (2012). The impact of transformational, transactional and non-leadership styles on employee job satisfaction in the German hospitality industry. Tourism and Hospitality Research, 12(4), 201-214.

Yun, S., Cox, J., Sims Jr, H. P., \& Salam, S. (2007). Leadership and teamwork: The effects of leadership and job satisfaction on team citizenship. International Journal of Leadership Studies, 2(3), 171-193.

Zakeri, S. (2015). The Investigation of Leadership Style and Its Effect on Citizens and Staffs in Saderat Bank in Tehran. European Online Journal of Natural and Social Sciences: Proceedings, $4(1$ (s)), pp-1047. 